\title{
Life style related to blood pressure and body weight in adolescence: Cross sectional data from the Young-HUNT study, Norway Magnus H Fasting1, Tom IL Nilsen ${ }^{2}$, Turid L Holmen ${ }^{1,3}$ and Torstein Vik*1
}

\author{
Address: ${ }^{1}$ Department of Public Health and General Practice Faculty of Medicine, Norwegian University of Science and Technology, N-7489 \\ Trondheim, Norway, ${ }^{2}$ Human Movements Science Programme, Faculty of Social Sciences and Technology Management, Norwegian University of \\ Science and Technology, Trondheim, Norway and ${ }^{3}$ HUNT Research Centre, Faculty of Medicine, Norwegian University of Science and Technology, \\ Verdal, Norway \\ Email: Magnus H Fasting - magnusf@stud.ntnu.no; Tom IL Nilsen - tom.nilsen@svt.ntnu.no; Turid L Holmen - turid.lingaas.holmen@ntnu.no; \\ Torstein Vik* - torstein.vik@ntnu.no \\ * Corresponding author
}

Published: 9 April 2008

BMC Public Health 2008, 8: III doi: I0.I |86/I47|-2458-8-III
Received: 21 June 2007

Accepted: 9 April 2008

This article is available from: http://www.biomedcentral.com/I47I-2458/8/III

(C) 2008 Fasting et al; licensee BioMed Central Ltd.

This is an Open Access article distributed under the terms of the Creative Commons Attribution License (http://creativecommons.org/licenses/by/2.0), which permits unrestricted use, distribution, and reproduction in any medium, provided the original work is properly cited.

\begin{abstract}
Background: The associations between physical activity, unhealthy dietary habits and cigarette smoking and blood pressure, overweight and obesity are well established in adulthood. This is not the case for similar associations in adolescence. Thus, the purpose of this study is to examine how physical activity, smoking status and dietary habits were related to overweight, obesity and blood pressure in a population of Norwegian adolescents.

Methods: Weight, height, systolic (SBP) and diastolic blood pressure (DBP) were measured, and body mass index (BMI) was calculated among 8408 adolescents who participated in a population based study in 1995-97 in the county of Nord-Trøndelag. Internationally accepted cut-off values were used to determine if the adolescents were overweight or obese. The adolescents also completed a detailed questionnaire including dietary habits, physical activity and smoking habits. We calculated adjusted mean blood pressures and odds ratios for being overweight or obese for different exposure categories of life style variables.

Results: Low levels of physically activity were associated with increased odds of being overweight (odds ratio (OR), I.4; 95\% confidence interval (Cl), I.I-I.8 in girls and OR, 2.0; 95\% Cl, I.6-2.5 in boys) or obese (girls: OR, 3.I; $95 \% \mathrm{Cl}$, I.6-6.0; boys: OR, 3.7; $95 \% \mathrm{Cl}, 2.1-6.4$ ). In addition, the least physically active girls had a $1.5 \mathrm{mmHg}$ higher mean DBP compared with the most active ( $\mathrm{p}$ trend $<0.00 \mathrm{I}$ ), and among boys this difference was $1.0 \mathrm{mmHg}$ ( $\mathrm{p}$-trend $<0.00 \mathrm{I}$ ). Smokers were more likely to be obese (OR, I.6; $95 \% \mathrm{Cl}$, I.I-2.5 in girls and I.4; $95 \% \mathrm{Cl}, 0.9-2.1$ in boys) compared with non-smokers. Smokers also had lower mean SBP than non-smokers; however, this finding was restricted to smokers with the lowest smoking exposure. Associations between dietary habits and weight status largely disappeared after adjusting for weight losing behaviour.
\end{abstract}

Conclusion: In this population of adolescents low levels of physical activity were associated with higher mean DBP and higher odds of overweight or obesity. Smoking was also associated with higher odds of overweight and obesity. The paradoxical associations between healthy dietary habits and overweight and obesity are most likely an effect of reverse causality. 


\section{Background}

High blood pressure, overweight and obesity in adulthood are well-known risk factors for cardiovascular disease. The development of these risk factors starts early in life and may be present already in childhood and adolescence [1-4].

Certain life style habits, including unhealthy dietary habits, cigarette smoking and inactivity are risk factors for cardiovascular disease that in part may be mediated or modulated through effects on blood pressure and body weight. These life style factors may also be established during childhood and adolescence, however, their associations with weight status and blood pressure in childhood and adolescence are less clear than in adulthood.

Low consumption of vegetables and fruits has been reported to be associated with increased blood pressure in adults [5], whereas in children and adolescents this was not supported in two reviews of the available evidence $[6,7]$. Physical inactivity is in itself an independent risk factor for cardiovascular disease in adulthood [8,9]. In addition, high physical activity is associated with reduced blood pressure [10] and lower body weight [11]. The associations between physical activity and blood pressure are not established in adolescence [12,13]. Irregularity of meals, such as breakfast skipping, is associated with overweight and obesity in childhood and adolescence [14], but the cause of this association remains unclear [15]. Finally, the effect of cigarette smoking on weight status and blood pressure is less well studied in adolescence than in adulthood where smoking is found to be associated with increased arterial stiffness [16] and dyslipidemia [17].

Thus, the purpose of this study was to examine how physical activity, smoking status and dietary habits were related to cardiovascular risk factors, such as elevated blood pressure, overweight and obesity in a population of Norwegian adolescents.

\section{Methods \\ Study population}

This population based cross sectional study comprises the youth part (Young-HUNT) of the second Nord-Trøndelag Health Study (HUNT II), carried out in 1995-1997. In Young-HUNT, all adolescents (13-19 years) in secondary or high school, living in the county of Nord-Trøndelag, Norway, were invited to participate. Among the 9917 adolescents who were invited to participate, 8950 (91\%) accepted the invitation and completed a comprehensive self-administered questionnaire, including questions on life style and health. Moreover, 8408 (85\%) of the adolescents chose to participate at a clinical examination that included measurements on height, weight and blood pressure by specially trained nurses.

Adolescents younger than $13(\mathrm{~N}=127)$ or older than 19 years $(\mathrm{N}=397)$ were excluded. Furthermore, all adolescents with incomplete data on blood pressure, height and weight were excluded, leaving 7908 (80\% of the 9917 invited) eligible for analysis. The total number of adolescents within this age group in Nord-Trøndelag was 10281 in 1995 [18], which means that our study population comprises $77 \%$ of the total population.

\section{Outcome measures}

Blood pressure was measured with the adolescent sitting comfortably in a chair. First, the upper arm circumference was measured to the closest centimetre. If the circumference was less than $24 \mathrm{~cm}$, a small cuff was used, if it was between $24 \mathrm{~cm}$ and $34 \mathrm{~cm}$ a medium cuff was used, and if it was $35 \mathrm{~cm}$ or more, a large cuff was used. The measurements were done using an automatic oscillometric, upon inflation technique (507 N monitor, Criticare System Inc.). The adolescents rested for two minutes before the first measurement, and the second and third measurements were done with one-minute intervals. Blood pressure was measured manually when an automatic recording could not be obtained. The mean value of the last two measurements was used in the analyses. If only one or two measurements were recorded, the single value $(\mathrm{N}=7)$, or the mean of the two $(\mathrm{N}=8)$ was used.

Height and weight were measured by trained nurses using internally standardized meter measures and weight scales. The subjects wore light clothes (T-shirts and trousers) without shoes. Height was read to the nearest centimetre $(\mathrm{cm})$ and weight to the nearest kilogram $(\mathrm{kg})$. Waist circumference was measured at the height of the umbilicus, using a tape measure to the nearest centimetre. Body mass index (BMI) was calculated as body weight (kg) divided by the squared value of height $(\mathrm{m})$. To define overweight and obesity, we used cut-off values for adolescents proposed by Cole et al [19].

\section{Study variables}

In the questionnaire, the adolescents were asked to indicate how often they consumed sweets and vegetables. Answer options were "more than once per day," "once per day," "every week, but not every day," "less than once per week" and "never." For the purpose of the present study, these responses were classified into three groups "once per day or more", "every week, but not every day" and "less than once per week." In addition the adolescents were asked to indicate whether they had breakfast "every day;" "4-6 days per week," "1-3 days per week" or "less than three days per week or never." 
The survey also had a question about weight loosing behaviour. The adolescents were asked to indicate their answer on the following question: "Are you trying to loose weight?" The options were "No, I'm comfortable with my weight," "No, but I need to loose weight" and "Yes."

Physical exercise was recorded as "Not during the average school day: How many days a week do you play sports, or exercise to the point where you breath heavily an/or sweat?" Response alternatives were: "every day," "4-6 days a week," "2-3 days a week," "1 day a week," "not every week, but at least one day every two weeks," "not every 14 days, but at least once a months," "less than once a month" and "never" [20]. The answers were grouped into three levels: " 4 days per week or more," "1-3 days per week" and "less than 1 day per week." These questions have been validated in a WHO survey [20].

Current smokers were defined as those who answered "yes, I smoke daily" or "yes, I smoke occasionally, but not daily" to the question: "do you smoke?" with five response options: "yes, I smoke daily," "yes, I smoke occasionally, but not daily," "no, I don't smoke, but I used to smoke daily," "no, I don't smoke, but I used to smoke occasionally" and "no, I don't smoke." Those who answered that they smoked daily were also asked to indicate the number of cigarettes they smoked every day, and how long they had been smokers. This information was used to calculate pack-years of smoking exposure among the daily smokers, and to categorize the daily smokers into three groups; group 1: those with less than one pack year, group 2: 1 - 2 pack years and group 3: smokers who had more than 2 pack years of smoking exposure. Adolescents in high school (3487) were also asked if they ever had tried marijuana.

\section{Ethics}

All participants, and parents of adolescents under the age of 16, signed a written consent to take part in the study. The study was approved by the Regional Committee for

Table I: Characteristics of the population
Medical Research Ethics and the Norwegian Data Inspectorate Board.

\section{Statistical analysis}

We computed mean diastolic and systolic blood pressure with $95 \%$ confidence interval (CI) within each category of the lifestyle factors, using a general linear model. In multivariable analysis, we adjusted for age and height, and in additional models we also evaluated potential confounding by BMI and smoking. In supplementary analysis, we assessed the independent effect of each lifestyle variable (i.e. smoking, diet (vegetable consumption) and physical activity) on blood pressure by mutual adjustment in the regression model.

Binary logistic regression was used to compute ageadjusted odds ratio (OR) with $95 \%$ CI for overweight or obesity associated with the different life style exposures. In additional multivariable analyses we adjusted for weight loosing behaviour, and we also examined the independent effect of each life style factor by mutual adjustment. Trend tests across exposure categories were calculated treating the categories as an ordinal variable in the regression model.

Given the sample size of boys $(\mathrm{N}=3926)$ and girls $(\mathrm{N}=$ 3982), and assuming a prevalence of an adverse life style in the population to be $20 \%$ (the case for smoking), the present study has a power of $80 \%$ to detect a difference in mean systolic blood pressure of approximately one percent (mean diff of $1.5 \mathrm{~mm} \mathrm{Hg}$ for boys, and $1.2 \mathrm{~mm} \mathrm{Hg}$ for girls; alpha of 0.05; Two-tailed). All data were analyzed using SPSS 14.0 for Windows (Copyright $\odot$ SPSS Inc., 1989-2005).

\section{Results}

Characteristics of the population are summarized in Table 1.

Blood pressure increased with increasing degree of overweight, both among girls and boys (Table 2). Obese girls

\begin{tabular}{|c|c|c|}
\hline Characteristic & Girls & Boys \\
\hline No. of participants & 3982 & 3926 \\
\hline Mean age, years (SD) & $15.9(1.65)$ & $15.9(1.64)$ \\
\hline Mean systolic blood pressure, $\mathrm{mmHg}(\mathrm{SD})$ & $119.6(10.60)$ & $125.1(12.73)$ \\
\hline Mean diastolic blood pressure, $\mathrm{mmHg}$ (SD) & $63.6(7.63)$ & $65.2(8.37)$ \\
\hline Mean weight, $\mathrm{kg}(\mathrm{SD})$ & $58.9(10.25)$ & $64.8(13.55)$ \\
\hline Mean height, cm (SD) & $165.5(6.33)$ & $174.3(9.48)$ \\
\hline Mean BMI, $\mathrm{kg} / \mathrm{m}^{2}(\mathrm{SD})$ & $21.4(3.30)$ & $21.2(3.25)$ \\
\hline Mean waist circumference, cm (SD) & $70.5(8.00)$ & $75.7(8.77)$ \\
\hline Percent overweight & 15.7 & 15.8 \\
\hline Percent obese & 2.8 & 2.9 \\
\hline
\end{tabular}


Table 2: Weight status and systolic (SBP) and diastolic (DBP) blood pressure ( $\mathrm{mm} \mathrm{Hg}$ )

\begin{tabular}{|c|c|c|c|c|c|c|c|}
\hline \multirow[b]{2}{*}{ Variables } & \multirow[b]{2}{*}{$\mathrm{N}$} & \multicolumn{3}{|c|}{$\mathrm{SBP}, \mathrm{mm} \mathrm{Hg}$} & \multicolumn{3}{|c|}{$\mathrm{DBP}, \mathrm{mm} \mathrm{Hg}$} \\
\hline & & Mean & $95 \% \mathrm{Cl}$ & P-trend & Mean & $95 \% \mathrm{Cl}$ & P-trend \\
\hline \multicolumn{8}{|l|}{ Females } \\
\hline Normal weight & 3355 & 118.3 & $1 \mid 8.0-118.7$ & -- & 63.2 & $62.9-63.5$ & -- \\
\hline Overweight & 517 & 124.5 & $123.6-125.5$ & -- & 65.1 & $64.5-65.7$ & -- \\
\hline Obese & 110 & 134.0 & $131.5-136.5$ & $<0.001$ & 70.1 & $68.7-71.5$ & $<0.001$ \\
\hline \multicolumn{8}{|l|}{ Males } \\
\hline Normal weight & 3307 & 123.7 & $123.3-124.1$ & -- & 64.7 & $64.4-65.0$ & -- \\
\hline Overweight & 505 & 131.1 & $130.0-132.3$ & -- & 66.8 & $66.1-67.6$ & -- \\
\hline Obese & 114 & 139.4 & $|37.0-14| .8$ & $<0.001$ & 71.0 & $69.1-72.8$ & $<0.001$ \\
\hline
\end{tabular}

had a mean systolic blood pressure of $134.0 \mathrm{~mm} \mathrm{Hg}$ (95\% CI: 131.5-136.5) compared to $118.3 \mathrm{~mm} \mathrm{Hg}$ (95\% CI: 118.0 - 118.7) in normal weight girls ( $\mathrm{p}$-trend < 0.001), and obese boys had a mean systolic blood pressure of $139.4 \mathrm{~mm}$ Hg (95\% CI: 137.0 - 141.8) compared with 123.7 mm Hg (95\% CI: 123.3 - 124.1) in boys with normal weight $(\mathrm{p}$-trend $<0.001)$.

Six hundred and thirty one $(15.8 \%)$ girls were trying to lose weight and 971 (24.4\%) girls indicated that they needed to lose weight, but did not actively try. Among boys, $183(4.7 \%)$ reported that they were trying to lose weight, while 462 (11.8\%) indicated that they needed to lose weight, but did not actively try to lose weight.

There were smoking data on 7767 of the adolescents. Of these, 1586 (20\%) were classified as smokers. A higher proportion of girls (23\%) than boys (18\%) were smokers ( $\mathrm{p}<0.001)$. Among the 1586 smokers, we had detailed information on smoking exposure in 1518, and 766 (50.5 $\%)$ of these were occasional and 752 (49.5\%) were daily smokers. Among the daily smokers 434 (57.7\%) had less than one pack year, 188 (25\%) had between one and two, and $130(17.3 \%)$ daily smokers had more than two pack years of smoking exposure. Thus, only four percent $(\mathrm{N}=$ 318 ) of the total population had a smoking exposure of one pack year or more. Among adolescents in high school, $330(9.4 \%)$ had ever tried marijuana.

\section{Clustering of life style factors}

To study clustering of adverse life style factors we used consumption of vegetables as a proxy for unhealthy diet, due to the observed inverse associations between consumption of sweets and breakfast frequency and high blood pressure or overweight. One unhealthy life style factor was present in 2615 (33.1\%) adolescents, whereas $1032(13.1 \%)$ had the combination of two and only 196 (2.5\%) adolescents had three unhealthy life style factors.
Among adolescents with one adverse life style factor, unhealthy diet was more common among boys ( $\mathrm{p}<$ 0.001), whereas a higher proportion of girls were less physical active $(\mathrm{p}<0.001)$ and were more often smokers $(\mathrm{p}<0.001)$. Among those with two adverse factors, smoking combined with low levels of physical activity was reported by 317 girls ( $8.0 \%)$ compared with 190 boys $(4.8 \%$; $<0.001)$, while physical activity combined with unhealthy diet was reported by 212 (5.4\%) boys compared with 161 girls $(4.0 \% ; \mathrm{p}=0.005)$.

\section{Blood pressure and life style}

Both in girls (Table 3) and boys (Table 4) lower levels of physical activity were associated with higher diastolic blood pressure.

Smokers also had lower systolic blood pressure compared with non-smokers (Tables 3 and 4). A similar, but weaker association was also observed for diastolic blood pressure. However, this difference in mean blood pressures was only present between never smokers and occasional smokers or smokers with less than one pack year of smoking exposure, whereas mean blood pressure values did not differ between never smokers and daily smokers with one pack year or more of smoking exposure (data not shown).

We also analyzed the association between dietary habits and blood pressure, and found increasing systolic and diastolic blood pressure with decreasing consumption of sweets both for girls (Table 3 ) and for boys (Table 4). In addition, among boys less regularity of breakfast was associated with increasing diastolic blood pressure (Table 4), whereas among girls decreasing consumption of vegetables was associated with increasing diastolic blood pressure (Table 3).

When BMI was added as a covariate increasing breakfast frequency was associated with increasing systolic blood pressure, both in girls ( $\mathrm{p}$-trend $=0.036$ ) and boys ( $\mathrm{p}$-trend $=0.048)$, whereas among boys, the association between 
Table 3: Association between life style factors and systolic (SBP) and diastolic (DBP) blood pressure (mm Hg) in girls.

\begin{tabular}{|c|c|c|c|c|c|c|c|}
\hline \multirow[b]{2}{*}{ Variables } & \multirow[b]{2}{*}{$\mathrm{N}$} & \multicolumn{3}{|c|}{$\mathrm{SBP}, \mathrm{mm} \mathrm{Hg}$} & \multicolumn{3}{|c|}{$\mathrm{DBP}, \mathrm{mm} \mathrm{Hg}$} \\
\hline & & Mean & $(95 \% \mathrm{Cl})$ & P-trend & Mean & $(95 \% \mathrm{Cl})$ & P-trend \\
\hline \multicolumn{8}{|l|}{ Regularity of breakfast* } \\
\hline Every day & 2539 & 119.7 & $119.3-120.1$ & -- & 63.6 & $63.3-63.8$ & -- \\
\hline 4-6 days per week & 543 & 119.1 & $118.2-119.9$ & -- & 63.6 & $63.0-64.3$ & -- \\
\hline I-3 days per week & 454 & 119.6 & $118.6-120.5$ & -- & 63.8 & $63.1-64.5$ & -- \\
\hline Less than I day per week & 403 & 119.8 & $118.8-120.8$ & 0.95 & 64.1 & $63.4-64.8$ & 0.18 \\
\hline \multicolumn{8}{|l|}{ Consumption of sweets* } \\
\hline Once per day or more & 371 & 117.8 & $1|6.7-1| 8.8$ & -- & 63.2 & $62.5-64.0$ & -- \\
\hline Every week, but not every day & 2797 & 119.7 & $119.3-120.0$ & -- & 63.6 & $63.3-63.8$ & -- \\
\hline Less than once per week & 746 & 120.3 & $119.6-121.1$ & $<0.001$ & 64.2 & $63.6-64.7$ & 0.02 \\
\hline \multicolumn{8}{|l|}{ Consumption of vegetables* } \\
\hline Once per day or more & $|53|$ & 119.4 & $118.9-120.0$ & -- & 63.5 & $63.1-63.9$ & -- \\
\hline Every week, but not every day & 1825 & 119.7 & $119.2-120.2$ & -- & 63.5 & $63.2-63.9$ & -- \\
\hline Less than once per week & 561 & 119.9 & $119.1-120.8$ & 0.32 & 64.5 & $63.9-65.1$ & 0.03 \\
\hline \multicolumn{8}{|l|}{ Physical activity* } \\
\hline 4 days or more per week & 889 & 119.5 & $1 \mid 8.8-120.1$ & -- & 62.8 & $62.3-63.3$ & -- \\
\hline 2-3 days per week & 1710 & 119.5 & $119.0-120.0$ & -- & 63.5 & $63.2-63.9$ & -- \\
\hline I day or less per week & 1359 & 119.7 & $119.2-120.3$ & 0.51 & 64.3 & $63.9-64.7$ & $<0.001$ \\
\hline \multicolumn{8}{|l|}{ Smoking status* } \\
\hline Non smokers & 3052 & 119.8 & $119.4-120.2$ & -- & 63.7 & $63.5-64.0$ & -- \\
\hline Smokers & 884 & 118.8 & $118.1-119.5$ & 0.01 & 63.3 & $62.8-63.8$ & 0.16 \\
\hline
\end{tabular}

*Adjusted for age and height

increasing diastolic blood pressure and decreasing breakfast frequency persisted ( $\mathrm{p}$-trend $=0.026$ ). When BMI was included, all associations with sweets except systolic blood pressure in boys, and all associations except diastolic blood pressure in girls disappeared (data not shown). Adjusting for marijuana exposure did not affect the blood pressure estimates.

Girls with three unhealthy life style factors had a mean diastolic blood pressure of $64.5 \mathrm{~mm} \mathrm{Hg}$ (95\% CI: 63.0 66.0) compared with 64.2 (95\% CI: 63.6 - 64.2) for those with two, and $63.3 \mathrm{~mm} \mathrm{Hg}(95 \% \mathrm{CI}: 62.9$ - 63.6) among those with no unhealthy life style factors (p-trend $=0.003$ ). A similar trend for boys was not present.

Multiple regression analyses suggested that age and height explained 3\% of the variance in systolic- and $5 \%$ of diastolic blood pressure in girls. In boys, age and height explained $17 \%$ of the variance in systolic- and $12 \%$ of the variance in diastolic blood pressure. In a model not including BMI, sweets and smoking contributed statistically significant to both mean systolic- as well as diastolic blood pressure in both sexes, whereas physical activity contributed to mean diastolic blood pressure in both sexes. However, adjusted R-square was only marginally affected, ( $\sim$ one percent) by each of these life style factors.
Consumption of breakfast and vegetables did not have independent effects in this model, except for a statistically significant effect of breakfast in diastolic blood pressure in boys.

When BMI was included in the models, the explained variance increased to $28 \%$ of systolic- and to $14 \%$ of diastolic blood pressure in boys, and to $13 \%$ of systolic- and $7 \%$ of diastolic blood pressure in girls. The effects of current life style factors were essentially the same, with the exception that the association between blood pressure and frequency of sweet consumption now largely disappeared, and only persisted for systolic blood pressure in boys.

\section{Overweight, obesity and life style}

Decreasing levels of physical activity were associated with increasing odds of being overweight or obese (Table 5). Mean waist circumference also increased with decreasing physical activity (Table 6).

Female smokers had higher odds of being obese compared to non-smokers. A similar, but weaker trend was present among boys (Table 5). Smokers also had higher mean waist circumference than never smokers (Table 6). These associations disappeared after adjusting for weight loosing behaviour. 
Table 4: Association between life style factors and systolic (SBP) and diastolic (DBP) blood pressure ( $\mathrm{mm} \mathrm{Hg}$ ) in boys.

\begin{tabular}{|c|c|c|c|c|c|c|c|}
\hline \multirow[b]{2}{*}{ Variables } & \multirow[b]{2}{*}{$\mathrm{N}$} & \multicolumn{3}{|c|}{$\mathrm{SBP}, \mathrm{mm} \mathrm{Hg}$} & \multicolumn{3}{|c|}{$\mathrm{DBP}, \mathrm{mm} \mathrm{Hg}$} \\
\hline & & Mean & $(95 \% \mathrm{Cl})$ & P-trend & Mean & $(95 \% \mathrm{Cl})$ & P-trend \\
\hline \multicolumn{8}{|l|}{ Regularity of breakfast* } \\
\hline Every day & 2840 & 125.2 & $124.8-125.6$ & -- & 65.0 & $64.7-65.2$ & -- \\
\hline 4-6 days per week & 404 & 125.7 & $124.6-126.8$ & -- & 65.8 & $65.0-66.5$ & -- \\
\hline I-3 days per week & 322 & 124.8 & $123.6-126.1$ & -- & 65.8 & $65.0-66.7$ & -- \\
\hline Less than I day per week & 273 & 125.1 & $123.7-126.5$ & 0.78 & 66.0 & $65.0-66.9$ & 0.005 \\
\hline \multicolumn{8}{|l|}{ Consumption of sweets* } \\
\hline Once per day or more & 536 & 123.3 & $122.3-124.2$ & -- & 64.6 & $63.9-65.2$ & -- \\
\hline Every week, but not every day & 2595 & 125.3 & $124.8-125.7$ & -- & 65.2 & $64.9-65.5$ & -- \\
\hline Less than once per week & 688 & 126.8 & $125.9-127.6$ & $<0.001$ & 65.5 & $65.0-66.1$ & 0.03 \\
\hline \multicolumn{8}{|l|}{ Consumption of vegetables* } \\
\hline Once per day or more & 1315 & 125.0 & $124.4-125.6$ & -- & 65.1 & $64.6-65.5$ & -- \\
\hline Every week, but not every day & 1700 & 125.3 & $124.8-125.9$ & -- & 65.2 & $64.8-65.6$ & -- \\
\hline Less than once per week & 788 & 125.6 & $124.8-126.4$ & 0.25 & 65.4 & $64.9-66.0$ & 0.29 \\
\hline \multicolumn{8}{|l|}{ Physical activity* } \\
\hline 4 days or more per week & 1275 & 124.6 & $124.0-125.3$ & -- & 64.6 & $64.2-65.0$ & -- \\
\hline $2-3$ days per week & 1483 & 125.5 & $124.9-126.1$ & -- & 65.3 & $64.9-65.7$ & -- \\
\hline I day or less per week & 1129 & 125.3 & $124.6-126.0$ & 0.14 & 65.6 & $65.2-66.1$ & $<0.001$ \\
\hline \multicolumn{8}{|l|}{ Smoking status* } \\
\hline Non smokers & 3129 & 125.4 & $125.0-125.8$ & -- & 65.3 & $65.0-65.6$ & -- \\
\hline Smokers & 702 & 123.9 & $123.1-124.8$ & 0.003 & 64.6 & $64.0-65.2$ & 0.04 \\
\hline
\end{tabular}

*Adjusted for age and height.

The OR of being overweight or obese increased with decreasing regularity of breakfast, and with decreasing frequency of sweets consumption (Table 5). Consistently, waist circumference increased with decreasing frequency of breakfast and sweets consumption (Table 6). However, after adjusting for weight loosing behaviour, these associations were largely attenuated; the OR of being overweight was reduced for boys who had breakfast less than one times a week from 1.6 (95\% CI: 1.1-2.1) to 1.1 (95\% CI 0.7-1.6) compared with boys who had breakfast daily, and for girls, the OR was reduced from 1.5 (95\% CI: $1.1-1.9)$ to 0.9 (95\% CI: 0.6-1.2). There were no associations between consumption of vegetables and being overweight or obese.

In multiple logistic regression analyses the effects of each adverse life style factor had independent effects on overweight, although the odds ratio for overweight in adolescents who had breakfast less frequently, or who were smokers were slightly attenuated or even became borderline statistically insignificant (data not shown). However, the odds of being overweight for the least active adolescents were unchanged, and for adolescents who consumed sweets seldom, the odds were even strengthened (data not shown).

\section{Discussion}

In this population of adolescents we found that low frequency of physical activity was associated with higher mean diastolic blood pressure, and with increased prevalence of overweight and obesity. Smokers were more likely to be overweight and obese, but they had lower blood pressure compared with non-smokers; however, in this youth population smoking exposure was of short duration. The finding that those who reported infrequent consumption of breakfast and sweets had a lower prevalence of overweight and obesity could to a large extent be explained by adolescents who wanted to lose weight, or who felt that they needed to lose weight.

The large sample size and the precision of the estimated associations make chance an unlikely explanation for the observed associations, and together with the proportions of exposed and unexposed individuals it ensures sufficient statistical power to detect very small differences.

The high participation rate and the independent administration of the questionnaires and the physical examination reduce the possibilities of selection or information bias. None the less, it can not be excluded that adolescents who are overweight or obese want to report more healthy 
Table 5: Odds ratio for overweight and obesity related to life style

\begin{tabular}{|c|c|c|c|c|c|c|c|c|}
\hline \multirow[b]{3}{*}{ Variables } & \multicolumn{4}{|c|}{ Girls } & \multicolumn{4}{|c|}{ Boys } \\
\hline & \multicolumn{2}{|c|}{ Overweight } & \multicolumn{2}{|c|}{ Obesity } & \multicolumn{2}{|c|}{ Overweight } & \multicolumn{2}{|c|}{ Obesity } \\
\hline & OR & $95 \% \mathrm{Cl}$ & OR & $95 \% \mathrm{Cl}$ & OR & $95 \% \mathrm{Cl}$ & OR & $95 \% \mathrm{Cl}$ \\
\hline \multicolumn{9}{|l|}{ Regularity of breakfast* } \\
\hline Every day & 1.0 & (Ref.) & 1.0 & (Ref.) & 1.0 & (Ref.) & 1.0 & (Ref.) \\
\hline 4-6 days per week & 1.2 & $(0.9-1.6)$ & 1.3 & $(0.7-2.3)$ & 1.3 & $(1.0-1.7)$ & 1.2 & $(0.7-2.2)$ \\
\hline I-3 days per week & 1.8 & $(1.4-2.3)$ & 2.6 & $(1.6-4.3)$ & 1.6 & $(1.2-2.2)$ & 1.8 & $(1.0-3.2)$ \\
\hline Less than I day per week & 1.5 & $(1.1-1.9)$ & 2.4 & $(1.4-4.0)$ & 1.6 & $(1.1-2.1)$ & 1.8 & $(1.0-3.4)$ \\
\hline \multicolumn{9}{|l|}{ Consumption of sweets* } \\
\hline Once per day or more & 1.0 & (Ref.) & 1.0 & (Ref.) & 1.0 & (Ref.) & 1.0 & (Ref.) \\
\hline Every week, but not every day & 1.7 & $(1.1-2.4)$ & 1.0 & $(0.5-2.0)$ & 1.5 & $(1.1-2.0)$ & 1.0 & $(0.6-1.9)$ \\
\hline Less than once per week & 3.2 & $(2.2-4.7)$ & 2.7 & $(1.3-5.8)$ & 2.3 & $(1.7-3.2)$ & 2.1 & $(1.1-4.1)$ \\
\hline \multicolumn{9}{|l|}{ Consumption of vegetables* } \\
\hline Once per day or more & 1.0 & (Ref.) & 1.0 & (Ref.) & 1.0 & (Ref.) & 1.0 & (Ref.) \\
\hline Every week, but not every day & 0.9 & $(0.7-1.0)$ & 0.6 & $(0.4-1.0)$ & 1.0 & $(0.8-1.2)$ & 0.8 & $(0.5-1.2)$ \\
\hline Less than once per week & 1.0 & $(0.7-1.3)$ & 0.8 & $(0.4-1.3)$ & 1.1 & $(0.8-1.3)$ & 1.4 & $(0.9-2.3)$ \\
\hline \multicolumn{9}{|l|}{ Physical activity* } \\
\hline 4 days or more per week & 1.0 & (Ref.) & 1.0 & (Ref.) & 1.0 & (Ref.) & 1.0 & (Ref.) \\
\hline 2-3 days per week & 1.2 & $(0.9-1.5)$ & 2.2 & $(1.1-4.3)$ & 1.4 & $(1.1-1.7)$ & 2.1 & $(1.2-3.7)$ \\
\hline I day or less per week & 1.4 & $(1.1-1.8)$ & 3.1 & $(1.6-6.0)$ & 2.0 & $(1.6-2.5)$ & 3.7 & $(2.1-6.4)$ \\
\hline \multicolumn{9}{|l|}{ Smoking status* } \\
\hline Non smokers & 1.0 & (Ref.) & 1.0 & (Ref.) & 1.0 & (Ref.) & 1.0 & (Ref.) \\
\hline Smokers & 1.1 & $(0.9-1.4)$ & 1.6 & $(1.1-2.5)$ & 1.2 & $(1.0-1.5)$ & 1.4 & $(0.9-2.1)$ \\
\hline
\end{tabular}

*Adjusted for age.

dietary habits than they in fact have. It may also be considered a limitation that the questions used to assess dietary habits have not been validated, however, similar questions have been used in comparable studies [21,22]. Thus, information bias may have contributed to some of the apparently paradoxical findings on the relation between dietary habits and being overweight or obese.

The homogeneity of the study population makes confounding by ethnicity and socioeconomic status unlikely. However, the results of the multivariable analyses suggested that the association between consumption of vegetables and blood pressure may have been confounded by other life style factors, and similar confounding may have contributed to the associations between smoking and overweight, and between irregular breakfast and overweight.

The most consistent finding in this study was that high levels of physical activity were associated with lower diastolic blood pressure and reduced risks of being overweight or obese. The finding of a small reduction in diastolic blood pressure with increasing physical activity was independent of the adolescents' BMI, and of other life style factors, and is consistent with studies in adults $[23,24]$ and with a study of adolescents who were hypertensive [13]. However, studies in adolescents have reported inconsistent results [25-27], and a recent meta analysis of intervention studies on physical activity and blood pressure in adolescents concluded that there was no significant effect of a short term intervention (8 - 36 weeks) in adolescents with normal blood pressure [12]. This may not be surprising, but may in fact be consistent with our finding that the life style factors evaluated in this study, including physical activity, only marginally contributed to the explained variance in blood pressure. Most probably, the variance in blood pressure at this age is mainly explained by genetic and early environmental factors (i.e. in utero or early infancy) [4]. However, we speculate that when adverse life style factors in adolescents persist into adulthood, their adverse effect on BP is likely to increase. Thus, our results may suggest that modifying life style habits in adolescence, emphasising the importance of regular physical activity could play a role in the prevention of later hypertension, even if the direct effect in this age group is small. 
Table 6: Waist circumference related to life style

\begin{tabular}{|c|c|c|c|c|c|c|c|c|}
\hline \multirow{3}{*}{ Variables } & \multicolumn{4}{|c|}{ Females } & \multicolumn{4}{|c|}{ Males } \\
\hline & \multicolumn{4}{|c|}{ Waist circumference, $\mathrm{cm}$} & \multicolumn{4}{|c|}{ Waist circumference, $\mathrm{cm}$} \\
\hline & $\mathrm{N}$ & Mean & $95 \% \mathrm{Cl}$ & P-trend & $N$ & Mean & $95 \% \mathrm{Cl}$ & P-trend \\
\hline \multicolumn{9}{|l|}{ Regularity of breakfast* } \\
\hline Every day & 2539 & 70.1 & $69.8-70.4$ & -- & 2840 & 75.5 & $75.2-75.8$ & -- \\
\hline 4-6 days per week & 543 & 70.8 & $70.1-7 \mid .4$ & -- & 404 & 76.4 & $75.6-77.2$ & -- \\
\hline I-3 days per week & 454 & 71.3 & $70.6-72.0$ & -- & 322 & 76.0 & $75.1-76.9$ & -- \\
\hline Less than I day per week & 403 & 71.7 & $70.9-72.4$ & $<0.001$ & 273 & 76.4 & $75.4-77.4$ & 0.04 \\
\hline \multicolumn{9}{|l|}{ Consumption of sweets* } \\
\hline Once per day or more & 371 & 69.7 & $68.9-70.5$ & -- & 536 & 74.7 & $74.0-75.4$ & -- \\
\hline Every week, but not every day & 2797 & 70.2 & $69.9-70.5$ & -- & 2595 & 75.6 & $75.3-75.9$ & -- \\
\hline Less than once per week & 746 & 72.0 & $71.5-72.6$ & $<0.001$ & 688 & 77.0 & $76.4-77.6$ & $<0.001$ \\
\hline \multicolumn{9}{|l|}{ Consumption of vegetables* } \\
\hline Once per day or more & $|53|$ & 70.6 & $70.2-71.0$ & -- & 1315 & 75.7 & $75.3-76.2$ & -- \\
\hline Every week, but not every day & 1825 & 70.3 & $70.0-70.7$ & -- & 1700 & 75.5 & $75.1-75.9$ & -- \\
\hline Less than once per week & 561 & 70.9 & $70.3-71.6$ & 0.71 & 788 & 76.2 & $75.6-76.8$ & 0.29 \\
\hline \multicolumn{9}{|l|}{ Physical activity* } \\
\hline 4 days or more per week & 889 & 70.2 & $69.6-70.7$ & -- & 1275 & 75.2 & $74.7-75.6$ & -- \\
\hline 2-3 days per week & 1710 & 70.4 & $70.0-70.7$ & -- & 1483 & 75.5 & $75.1-75.9$ & -- \\
\hline I day or less per week & 1359 & 70.9 & $70.4-71.3$ & 0.03 & 1129 & 76.5 & $76.0-76.9$ & $<0.001$ \\
\hline \multicolumn{9}{|l|}{ Smoking status* } \\
\hline Non smokers & 3052 & 70.3 & $70.0-70.6$ & -- & 3129 & 75.5 & $75.2-75.8$ & -- \\
\hline Smokers & 884 & 71.2 & $70.7-71.7$ & 0.003 & 702 & 76.4 & $75.8-77.0$ & 0.01 \\
\hline
\end{tabular}

*Adjusted for age

There was an association between low consumption of sweets and higher systolic and diastolic blood pressures, both among girls and boys. However, these relationships were significantly attenuated when BMI was included in the model. This fact, in addition to the similar relationship found between overweight and sweets consumption might indicate that this effect is mediated through BMI. We also found an association between less frequent breakfast consumption and increasing diastolic blood pressure in boys, and multivariable analyses suggested that this effect was independent of other life style factors. It may be reasonable to speculate that this effect could also be mediated via an effect on BMI; however, the association was weak, only among boys and only for diastolic blood pressure. Thus, the finding should be interpreted cautiously.

The somewhat paradoxical finding that smokers have lower blood pressure than non-smokers has also been reported by others [28-30]. The mechanism behind this finding is unclear. Charlton and While found in a prospective study that children with low blood pressure at age 10 were more likely to be smokers by age 16 years [31]. In our study, occasional smokers had lower blood pressures than never smokers while there were no differences between daily smokers with greater than one pack year smoking exposure and never smokers. This may suggest that the decreased blood pressure among smokers is a transient phenomenon, or as the study of Charlton and While suggests, that smokers have lower blood pressure before they start smoking. As duration of smoking increases this difference may level off. Since, only a very low proportion of adolescents in this study had smoked more than one pack year, we were not able to address this question further.

The finding that adolescents with low physical activity were more likely to be overweight or obese compared with adolescents who were most active is in agreement with several longitudinal studies $[32,33]$, as well as with a large systematic review including 162305 adolescents from 34 countries [34]. Moreover, the multivariable analyses suggested that this association was robust and independent of other life style factors.

The inverse associations between regularity of breakfast and overweight and obesity are well known, and several explanations have been postulated [35-38]. We have already discussed the possibility of information bias. 
Moreover, the associations between this and other dietary habits and overweight or obesity were weakened or even disappeared when we adjusted for weight losing behaviour, or for other life style variables. As indicated in a recent review [39], cross sectional studies on this topic may be subject to the presence of reverse causation. That is, overweight subjects are skipping breakfast in response to their weight; skipping breakfast is not causing overweight. Most likely the same mechanism may explain the finding that adolescents who seldom consumed sweets, were more likely to be overweight or obese.

In line with other studies [40], smoking was associated with increased risks of being overweight and obese, however, logistic regression analyses suggested that this association partly may be confounded by other life style factors.

It may be considered a positive finding that only $15 \%$ of the adolescents had two or more unhealthy life style factors. However, among girls, higher diastolic blood pressure was associated with increasing number of unhealthy life style habits, and this may suggest a dose-response effect which may be a further indication of a cause - effect relation between these adverse life style factors and risk for later hypertension.

\section{Conclusion}

The robust and consistent finding of this study is that low levels of physical activity were associated with higher mean diastolic blood pressure and with higher odds of being overweight and obese. Smokers also had higher odds of being overweight and obese, and smokers in addition had lower blood pressure than non-smokers; however, the latter finding may be a transitory phenomenon. The paradoxical associations between healthy dietary habits and overweight and obesity are most likely an effect of reverse causality.

\section{Competing interests}

The author(s) declare that they have no competing interests.

\section{Authors' contributions}

MHF analysed the data and drafted the article. TILN advised on statistics and critically revised the manuscript. TLH participated in the questionnaire preparation, discussion on the study design and critically revised the manuscript. TV advised on statistics, participated in the discussion on the study design and critically revised the manuscript. All authors read and approved the final manuscript.

\section{Acknowledgements}

The Youth part of Nord-Trøndelag Health Study (The Young-HUNT

Study) is a collaboration between HUNT Research Centre, Faculty of Med- icine, The Norwegian University of Science and Technology (NTNU, Verdal), Norwegian Institute of Public Health, and Nord-Trøndelag County Council. We thank the Norwegian Research Council for financial support.

\section{References}

I. Bao W, Threefoot SA, Srinivasan SR, Berenson GS: Essential hypertension predicted by tracking of elevated blood pressure from childhood to adulthood: The Bogalusa heart study. American Journal of Hypertension 1995, 8:657-665.

2. Newman WP, Freedman DS, Voors AW, Gard PD, Srinivasan SR, Cresanta JL, Williamson GD, Webber LS, Berenson GS: Relation of serum lipoprotein levels and systolic blood pressure to early atherosclerosis. The Bogalusa Heart Study. N Engl J Med I 986, 3 | 4: |38-| 44.

3. Serdula MK, Ivery D, Coates RJ, Freedman DS, Williamson DF, Byers $\mathrm{T}$ : Do obese children become obese adults? A review of the literature. Prev Med 1993, 22:167-177.

4. Barker DJ: Adult consequences of fetal growth restriction. Clin Obstet Gynecol 2006, 49:270-283.

5. Appel LJ, Moore TJ, Obarzanek E, Vollmer WM, Svetkey LP, Sacks FM, Bray GA, Vogt TM, Cutler JA, Windhauser MM, Lin PH, Karanja N, Simons-Morton D, McCullough M, Swain J, Steele P, Evans MA, Miller ER, Harsha DW, The DASH Collaborative Research Group: A Clinical Trial of the Effects of Dietary Patterns on Blood Pressure. N Engl J Med 1997, 336: I I I7- I I 24.

6. Simons-Morton DG, Obarzanek E: Diet and blood pressure in children and adolescents. Pediatr Nephrol 1997, I I:244-249.

7. Couch SC, Daniels SR: Diet and blood pressure in children. Curr Opin Pediatr 2005, I 7:642-647.

8. Sesso HD, Paffenbarger RS Jr, Lee IM: Physical Activity and Coronary Heart Disease in Men : The Harvard Alumni Health Study. Circulation 2000, 102:975-980.

9. Manson JAE, Hu FB, Rich-Edwards JW, Colditz GA, Stampfer MJ, Willett WC, Speizer FE, Hennekens CH: A Prospective Study of Walking as Compared with Vigorous Exercise in the Prevention of Coronary Heart Disease in Women. N Engl J Med I999, 341:650-658.

10. Fagard RH: Exercise characteristics and the blood pressure response to dynamic physical training. Med Sci Sports Exerc 200I, 33:S484-S492.

II. K S, H G, P OR, C DM: Exercise for overweight or obesity. Cochrane Database of Systematic Reviews 2006.

12. Kelley GA, Kelley KS, Tran ZV: The effects of exercise on resting blood pressure in children and adolescents: a meta-analysis of randomized controlled trials. Prev Cardiol 2003, 6:8-16.

13. Alpert BS, Wilmore JH: Physical Activity and Blood Pressure in Adolescents. In Pediatric Exercise Science Volume 6. Human Kinetics Publishers, Inc.; 1994:36I-380.

14. Rampersaud GC, Pereira MA, Girard BL, Adams J, Metzl JD: Breakfast Habits, Nutritional Status, Body Weight, and Academic Performance in Children and Adolescents. Journal of the American Dietetic Association 2005, 105:743-760.

15. Rodriguez $\mathrm{G}$, Moreno LA: Is dietary intake able to explain differences in body fatness in children and adolescents? Nutrition, Metabolism and Cardiovascular Diseases 2006, 16:294-301.

16. Mahmud A, Feely J: Effect of Smoking on Arterial Stiffness and Pulse Pressure Amplification. Hypertension 2003, 4I:183-187.

17. Masulli M, Riccardi G, Galasso R, Vaccaro O: Relationship between smoking habits and the features of the metabolic syndrome in a non-diabetic population. Nutrition, Metabolism and Cardiovascular Diseases 2006, 16:364-370.

18. Statistics Norway [http://www.ssb.no]

19. Cole TJ, Bellizzi MC, Flegal KM, Dietz WH: Establishing a standard definition for child overweight and obesity worldwide: international survey. $B M / 2000,320: 1240-1243$.

20. King A, Wold B, Tudor-Smith C, Harel Y: The health of youth. A cross-national survey. WHO Reg Publ Eur Ser 1996, 69: 1-222.

21. Delva J, O'Malley PM, Johnston LD: Racial/ethnic and socioeconomic status differences in overweight and health-related behaviors among American students: national trends 19862003. J Adolesc Health 2006, 39:536-545.

22. Delva J, Johnston LD, O'Malley PM: The epidemiology of overweight and related lifestyle behaviors: racial/ethnic and socioeconomic status differences among American youth. $\mathrm{Am} J$ Prev Med 2007, 33:SI78-SI86. 
23. Whelton SP, Chin A, Xin X, He J: Effect of Aerobic Exercise on Blood Pressure: A Meta-Analysis of Randomized, Controlled Trials. Ann Intern Med 2002, I 36:493-503.

24. Kelley GA, Kelley KS: Progressive Resistance Exercise and Resting Blood Pressure : A Meta-Analysis of Randomized Controlled Trials. Hypertension 2000, 35:838-843.

25. Ekelund U, Brage S, Froberg K, Harro M, Anderssen SA, Sardinha LB, Riddoch C, Andersen LB: TV Viewing and Physical Activity Are Independently Associated with Metabolic Risk in Children: The European Youth Heart Study. PLoS Medicine 2006, 3:e488.

26. Andersen LB, Harro M, Sardinha LB, Froberg K, Ekelund U, Brage S, Anderssen SA: Physical activity and clustered cardiovascular risk in children: a cross-sectional study (The European Youth Heart Study). Lancet 2006, 368:299-304.

27. Brage S, Wedderkopp N, Ekelund U, Franks PW, Wareham NJ, Andersen LB, Froberg K: Features of the Metabolic Syndrome Are Associated With Objectively Measured Physical Activity and Fitness in Danish Children: The European Youth Heart Study (EYHS). Diabetes Care 2004, 27:2|4|-2|48.

28. Ko GTC, Chan JCN, Tsang LWW, Critchley JAJH, Cockram CS: Smoking and diabetes in Chinese men. Postgrad Med J 200I, 77:240-243.

29. Steenkamp E, Jooste PL, Christopher KJ: The prevalence of smoking and its relationship to other coronary risk factors in a rural white community. S Afr Med J 1988, 73:402-405.

30. Mikkelsen KL, Wiinberg N, Hoegholm A, Christensen HR, Bang LE, Nielsen PE, Svendsen TL, Kampmann JP, Madsen NH, Bentzon MW: Smoking related to 24-h ambulatory blood pressure and heart rate: a study in $\mathbf{3 5 2}$ normotensive Danish subjects. Am J Hypertens 1997, 10:483-491.

31. Charlton A, While D: Blood pressure and smoking: observations on a national cohort. Arch Dis Child 1995, 73:294-297.

32. Kimm SYS, Glynn NW, Obarzanek E, Kriska AM, Daniels SR, Barton BA, Liu K: Relation between the changes in physical activity and body-mass index during adolescence: a multicentre longitudinal study. The Lancet 2005, 366:301-307.

33. Berkey CS, Rockett HRH, Field AE, Gillman MW, Frazier AL, Camargo CA, MD J, Colditz GA: Activity, Dietary Intake, and Weight Changes in a Longitudinal Study of Preadolescent and Adolescent Boys and Girls. Pediatrics 2000, I 05:e56.

34. Janssen I, Katzmarzyk PT, Boyce WF, Vereecken C, Mulvihill C, Roberts C, Currie C, Pickett W: Comparison of overweight and obesity prevalence in school-aged youth from 34 countries and their relationships with physical activity and dietary patterns. Obesity Reviews 2005, 6:123-132.

35. Wolfe WS, Campbell CC, Frongillo EA Jr., Haas JD, Melnik TA: Overweight schoolchildren in New York State: prevalence and characteristics. Am J Public Health I994, 84:807-8I 3.

36. Siega-Riz AM, Popkin BM, Carson T: Trends in breakfast consumption for children in the United States from I 965-I99I. Am J Clin Nutr 1998, 67:748S-7756.

37. Affenito SG, Thompson DR, Barton BA, Franko DL, Daniels SR, Obarzanek E, Schreiber GB, Striegel-Moore RH: Breakfast Consumption by African-American and White Adolescent Girls Correlates Positively with Calcium and Fiber Intake and Negatively with Body Mass Index. Journal of the American Dietetic Association 2005, 105:938-945.

38. Zullig K, Ubbes VA, Pyle J, Valois RF: Self-Reported Weight Perceptions, Dieting Behavior, and Breakfast Eating Among High School Adolescents. Journal of School Health 2006, 76:87-92.

39. Newby PK: Are Dietary Intakes and Eating Behaviors Related to Childhood Obesity? A Comprehensive Review of the Evidence. The Journal of Law, Medicine \& Ethics 2007, 35:35-60.

40. Gelber RP, Gaziano JM, Manson JAE, Buring JE, Sesso HD: A Prospective Study of Body Mass Index and the Risk of Developing Hypertension in Men. American Journal of Hypertension 2007 20:370-377.

\section{Pre-publication history}

The pre-publication history for this paper can be accessed here:

http://www.biomedcentral.com/1471-2458/8/111/pre pub
Publish with Biomed Central and every scientist can read your work free of charge

"BioMed Central will be the most significant development for disseminating the results of biomedical research in our lifetime. "

Sir Paul Nurse, Cancer Research UK

Your research papers will be:

- available free of charge to the entire biomedical community

- peer reviewed and published immediately upon acceptance

- cited in PubMed and archived on PubMed Central

- yours - you keep the copyright
BioMedcentral 